\title{
A polarizing microscopic analysis of the calcified masses based on their collagen fibre orientation in peripheral ossifying fibroma
}

This article was published in the following Dove Press journal:

Pathology and Laboratory Medicine International

10 July 2010

Number of times this article has been viewed

\author{
Devi C Shetty' \\ Aadithya B Urs' \\ Puneet Ahuja² \\ Harish C Rai' \\ Seema Sikka' \\ Anshuta Sahu' \\ Yuthicka Sirohi' \\ 'Department of Oral and Maxillofacial \\ Pathology and Microbiology, I.T.S-CDSR, \\ Muradnagar, Ghaziabad, Uttar Pradesh, \\ India; ${ }^{2}$ ITS Dental College, Greater \\ Noida, Uttar Pradesh, India
}

\begin{abstract}
Peripheral ossifying fibroma (POF) is a reactive gingival lesion exhibiting a diverse spectrum of histopathology, accounting for $9.6 \%$ of gingival lesions. This study encompasses a detailed clinical, radiographic, and histopathological analysis of 15 cases of POF, retrieved from departmental archives. The following cases were subsequently stained with a histochemical stain (van Gieson) and observed under a polarizing microscope. This study is an effort to analyze the diverse spectrum of mineralized components and their surrounding tissues. Clinically, the study revealed a female predilection $(73 \%)$ with the second and third decade commonly affected. The most common site was interdental papilla of anterior region, presenting itself as pink and sessile nodular mass. Radiographic examination revealed $93 \%$ of the cases showing no manifestation on the radiograph. Histopathological analysis showed $73 \%$ of the cases exhibited a fibrocellular connective tissue stroma with plump fibroblasts around the mineralized areas. The collagen was predominantly mature. Polarizing microscopy of the mineralized tissue revealed that $53 \%$ of the cases showed only woven bone, $20 \%$ showed combination of lamellar bone and cellular cementum, $13.3 \%$ showed only cementum (cellular and acellular) with another $13.3 \%$ showing mixture of woven and lamellar bone. Thus, the concept/theory that POF develops from cells of PDL/periosteum is emphasized. The undifferentiated mesenchymal cells have an inherent proliferative potential and can form bone or cementum, whose nature can be confirmed by polarizing microscope. This origin from periodontal ligament can also account for the high recurrence rate seen in POF.
\end{abstract}

Keywords: histogenesis, mineralized masses, polarizing microscopy

\section{Introduction}

Gingiva, being the prominent, easily accessible, and commonly offended part of the oral cavity, has clinically been involved in the presentation of numerous pathological lesions and conditions. These gingival growths could result from various etiological assumptions, like from simple localized trauma-reactive lesions to the more generalized diverse pathological lesion/conditions. The reactive lesions are commonly subdivided due to their occurrence on the gingiva as pyogenic granuloma, peripheral ossifying fibroma (POF), peripheral giant cell granuloma, and peripheral fibroma. These are usually present with a nonspecific clinical picture/presentation/ appearance, and these might have to be distinguished based on the different histological features within them. Among the above-mentioned proliferative lesions of the gingiva is POF, a reactive lesion occurring commonly with an overall incidence of $9.6 \%$ of gingival lesions. ${ }^{1}$ These lesions clinically are slow-growing, red or pink nodular masses, which are sessile or pedunculated, frequently involving anterior
Department of Oral and Maxillofacial Pathology and Microbiology, I.T.S-CDSR Muradnagar, Ghaziabad-20I206,

Uttar Pradesh, India

Tel +9l 9873525076

Email shettydivya76@rediffmail.com 
maxilla with a strong localization to the interdental papilla of incisor/cuspid region. They could also be seen randomly in any part of gingiva. A higher incidence rate in females than males is noticed, with the second decade predominantly being affected. POF usually measure $<1.5 \mathrm{~cm}$ in diameter, but patients with lesions of 6-9 $\mathrm{cm}$ diameter have been reported. ${ }^{2}$ Histologically, POF exhibits intact or ulcerated stratified squamous epithelium; the lamina propria presents highly cellular fibrous component with central areas of calcifications, which may be bone, cementum-like material, dystrophic calcifications or an amalgamation of each. ${ }^{3}$

Prognosis is good, but some instances of recurrence have been reported regularly in various studies. Incidence of recurrence has been put at $16 \%-20 \%$ by various studies. ${ }^{4-6}$ Reasons for recurrence include (1) incomplete removal of lesion, (2) failure to eliminate local irritants, (3) difficulty in access during surgical manipulation due to intricate location of POF being present usually at interdental areas. Deep excisions have been preferred as interjection to these recurrences.

Different researchers have enumerated various reasons for the diverse clinicopathological behavior/spectrum of these lesions. This study aims to analyze the histological spectrum seen in the differing cases of POF and to hypothesize its possible histogenesis through interpretation of the mineralized components in POF with the use of polarizing microscopy.

\section{Materials and method}

In this study, 15 cases of previously diagnosed POF were subjected to clinical and histopathological analysis, which were retrieved from the departmental archives between March 2005 and December 2008. All the 15 cases were analyzed by 3 different observers separately. The radiographs were assessed wherever necessary to assess any probable bone loss if present. Clinically, the cases were examined for the following criteria's: (1) age, (2) sex, (3) site of the lesion, and (4) size of the lesion. Radiographically, the cases were evaluated for presence or absence of bone resorption. Fifteen tissue blocks of the selected cases were retrieved for sectioning using LEICA microtome and 3- $\mu \mathrm{m}$ thick hematoxylin-eosin (H \& E) sections were prepared. H \& Estained sections were assessed for (1) fibroblast population, (2) nature of collagen, and (3) nature of the stroma around the mineralized tissue.

To evaluate the mineralized masses, $3-\mu \mathrm{m}$ thick sections were taken as previously mentioned and stained with van Gieson and subjected to polarizing microscopic analysis (Model BX41; Olympus System Microscope). ${ }^{7}$ The varying polarizing patterns were further evaluated to quantitate the type of mineralized tissue present in the section. The criteria's used were based on the works of Giansanti ${ }^{8}$ who pioneered the identification of these mineralized masses using polarizing microscopy.

\section{Results}

The clinical features were enumerated and grouped (Table 1). Majority of the cases showed a female predilection $(73 \%)$ with the second and third decade commonly affected. The most common site being affected is the interdental papilla of the incisor/cuspid region (Figure 1). Most of the lesions measured $0.5-1.5 \mathrm{~cm}$ in size/dimensions. Clinically, the lesions were seen as red to pink nodular mass, which were usually sessile and firm in consistency. The radiographic findings varied from none to slight saucerization of the cortical bone. Ninety-three percent of the cases showed no radiographic manifestations.

Various histopathological features were summarized and are grouped in Table 2. A majority of the cases (73\%) showed a fibrocellular connective tissue stroma (Figure 2) with plump fibroblasts around the mineralized areas (Figure 3). The collagen seen was predominantly mature with few cases also showing areas of hyalinization.

Table I Comparison of clinical features

\begin{tabular}{|c|c|c|c|c|}
\hline \multirow[t]{2}{*}{ S no } & \multicolumn{4}{|c|}{ Clinical features } \\
\hline & Age, y & Sex & Site & Size \\
\hline 1 & 16 & $\mathrm{~F}$ & Interdental papilla b/w 12 and 13 & $\mathrm{I} \times 1.5 \mathrm{~cm}$ \\
\hline 2 & 50 & $\mathrm{~F}$ & $\begin{array}{l}\text { Incisive papilla in respect to II } \\
\text { and } 21\end{array}$ & $1.5 \times 1.5 \mathrm{~cm}$ \\
\hline 3 & 25 & $M$ & Interdental papilla b/w 13 and 16 & $1.5 \times 1 \mathrm{~cm}$ \\
\hline 4 & 24 & $M$ & Interdental papilla b/w 24 and 25 & $\mathrm{I} \times \mathrm{I} \mathrm{cm}$ \\
\hline 5 & 18 & $\mathrm{~F}$ & Interdental papilla b/w 34 and 36 & $1.5 \times 1 \mathrm{~cm}$ \\
\hline 6 & 22 & $\mathrm{~F}$ & Interdental papilla b/w 23 and 24 & $0.5 \times 1 \mathrm{~cm}$ \\
\hline 7 & 24 & $\mathrm{~F}$ & Interdental papilla b/w I4 and I5 & $1 \times 1.2 \mathrm{~cm}$ \\
\hline 8 & 28 & $\mathrm{~F}$ & Lingual aspect in respect to $32-34$ & $1.5 \times 1 \mathrm{~cm}$ \\
\hline 9 & 19 & $M$ & $\begin{array}{l}\text { Labial aspect in respect to } \mathrm{II} \text { and } \\
12\end{array}$ & $\mathrm{I} \times 1.5 \mathrm{~cm}$ \\
\hline 10 & 22 & $\mathrm{~F}$ & Interdental papilla b/w 32 and 33 & $\mathrm{I} \times \mathrm{I} \mathrm{cm}$ \\
\hline II & 24 & $\mathrm{~F}$ & Interdental papilla b/w 12 and 13 & $0.5 \times 1 \mathrm{~cm}$ \\
\hline 12 & 30 & $M$ & $\begin{array}{l}\text { Labial aspect in respect to } 44 \text { and } \\
45\end{array}$ & $0.5 \times 1 \mathrm{~cm}$ \\
\hline 13 & 21 & $\mathrm{~F}$ & Interdental papilla b/w 22 and 23 & $\mathrm{I} \times \mathrm{I} \mathrm{cm}$ \\
\hline 14 & 25 & $\mathrm{~F}$ & Interdental papilla b/w 24 and 25 & $0.5 \times 1 \mathrm{~cm}$ \\
\hline 15 & 27 & $\mathrm{~F}$ & $\begin{array}{l}\text { Lingual aspect in respect to } 33 \\
\text { and } 34\end{array}$ & $\mathrm{I} \times 1.5 \mathrm{~cm}$ \\
\hline
\end{tabular}




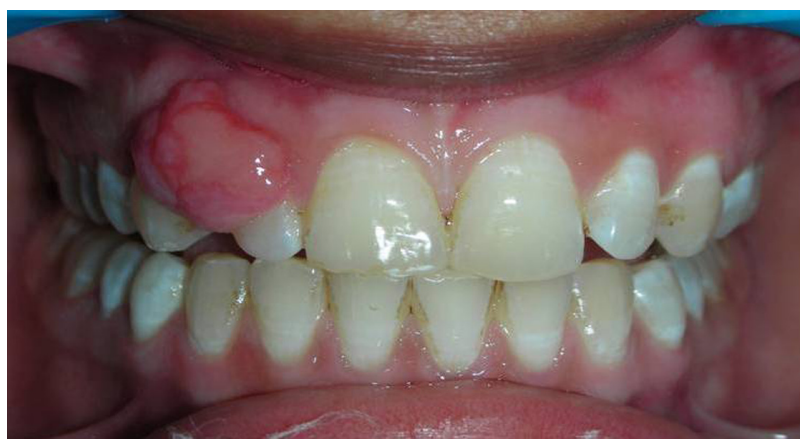

Figure I Clinical photograph showing typical presentation of peripheral ossifying fibroma involving the interdental papilla of 12 and 13 .

On subjecting these 15 cases to polarizing microscopy varying characteristic patterns were seen (Table 3). Of the 15 cases, 8 cases showed the presence of only woven bone ${ }^{8}$ (53\%; Figure 4), 3 cases showed the presence of lamellar bone in combination with cellular cementum (20\%; Figure 5), whereas 2 cases showed the exclusive presence of cementum (cellular and acellular; Figure 6) and 2 cases showed mixture of woven and lamellar bones (13\%), respectively.

\section{Discussion}

Previously, POF has been referred by many synonymous terms such as peripheral fibroma with calcifications, ossifying fibrous epulis, and calcifying fibroblastic granuloma. It was Gardner ${ }^{9}$ in 1982, who advocated the term POF for a lesion that is reactive in nature and that it is not the extraosseous counterpart of central ossifying fibroma of maxilla and mandible. This was also supported by a study conducted by Sousa et $\mathrm{al}^{10}$ who used proliferative markers such as AgNORs and PCNA, which showed that there was increased proliferative activity in central ossifying fibroma when compared with POF.

This study represents the plethora of clinicopathological presentations as evident in POF. In the review of our 15 cases, POF was seen to affect younger individuals, with majority of cases seen in second and third decades of life (16-28 years). This correlates well with the literature as reported by Bhasker and Jacoway. ${ }^{11}$ Only 1 case in this study was seen involving a 50-year-old female patient. The high female affliction $(11: 4 ; \mathrm{F}>\mathrm{M})$ in this study is in keeping with similar findings in the literature. ${ }^{11}$ The consideration of POF being present in the close vicinity to the tooth-bearing/ teeth-bearing areas of the jaw needs to be emphasized. This association as previously substantiated by Waldron ${ }^{12}$ has also been observed in this study. Eversole and Rovin ${ }^{13}$ has shown that the most common location of involvement for POF is the anterior maxilla with a strong localization to the interdental papilla of incisor/cuspid region. This study also showed similar findings as $66 \%$ of the cases were seen to involve the interdental papilla of maxillary incisor/cuspid region. POF usually measures $<1.5 \mathrm{~cm}$ in diameter, but patients with lesions of 6 and $9 \mathrm{~cm}$ diameter have been reported. ${ }^{2}$ The lesions studied in this study usually were $0.5-1.5 \mathrm{~cm}$ in diameter. Clinically, POF occurs as a solitary, pink to red firm nodular lesion, which may be sessile/pedunculated. ${ }^{14}$

Table 2 Histopathological features

\begin{tabular}{|c|c|c|c|}
\hline Case no & Fibroblast population & Nature of collagen & $\begin{array}{l}\text { Nature of stroma } \\
\text { around the } \\
\text { mineralized tissue }\end{array}$ \\
\hline I & Plump & Mature with hyalinized areas & Fibrocellular \\
\hline 2 & Plump & Mature with hyalinization & $\begin{array}{l}\text { Mature and } \\
\text { fibrocellular }\end{array}$ \\
\hline 3 & Plump & Mature with hyalinized areas & Fibrocellular \\
\hline 4 & Flattened & Mature & \\
\hline 5 & Plump & Mature & Fibrocellular \\
\hline 6 & Flattened with few plump & Mature & Mature \\
\hline 7 & Flattened and plump & Mature & Fibrocellular \\
\hline 8 & Plump & Mature & Fibrocellular \\
\hline 9 & Plump & Mature & Fibrocellular \\
\hline 10 & Flattened and plump & Mature with hyalinized areas & Fibrocellular \\
\hline I I & Plump & Mature & Fibrocellular \\
\hline 12 & Plump & Mature & Fibrocellular \\
\hline 13 & Flattened & Mature & Mature \\
\hline 14 & Plump & Mature with hyalinized areas & Fibrocellular \\
\hline 15 & Plump & Mature & Mature \\
\hline
\end{tabular}




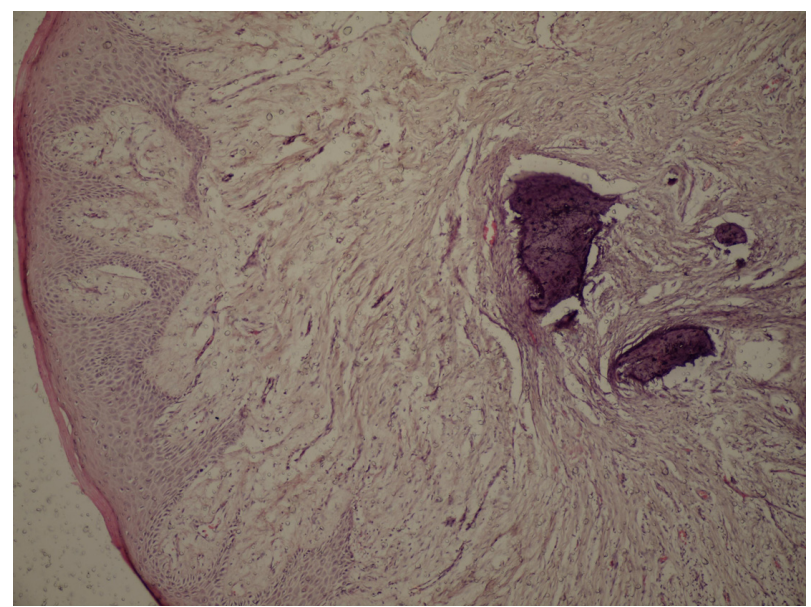

Figure 2 Section showing mineralized tissue in fibrocellular connective tissue stroma (hematoxylin-eosin, original magnification $\times 10$ ).

Histopathologically, several variations were observed with equal number of cases showing ulcerated epithelium and others showing hyperplastic epithelium. In this study, three-fourth of cases showed fibrocellular connective tissue stroma with fibroblast showing moderate-high activity. Plump fibroblasts with vesicular nucleus were a common feature. The plump fibroblasts can be considered to be representative of the undifferentiated mesenchymal cells arising from PDL, whereas if the fibroblasts are spindle shaped, it may represent a metaplastic change as seen in pyogenic granuloma. A very characteristic feature of POF is the presence of high cellularity around the mineralized tissue as stated by Eversole and Rovin, ${ }^{13}$ which helps in differentiating the connective tissue stroma from other peripheral lesions like pyogenic granuloma. This high cellularity around the mineralized tissue was predominant in the case study.

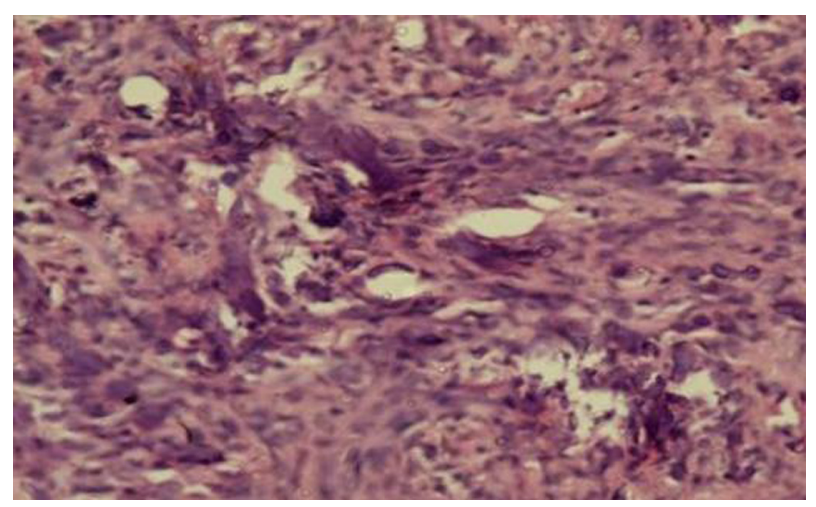

Figure 3 Section showing high fibroblastic activity around mineralized masses (hematoxylin-eosin, original magnification $\times 40$ ).
Buchner and Hansen ${ }^{1}$ reported that there are 3 types of mineralized tissue in POF: dystrophic calcification, bone (woven or lamellar), and cementum-like material. The distinction between these mineralized masses is quite arbitrary in routine $\mathrm{H} \& \mathrm{E}$ sections. With the advent of polarizing microscopy, its efficacy in accurately identifying these mineralized masses has been advocated by Waldron and Giansanti ${ }^{15}$ in their various studies conducted on fibroosseous lesions.

These principles were used to identify the exact nature of the mineralized masses in POF, and the results are evident in Table 3; thus, a clear distinction between woven bone, lamellar bone, cellular and acellular cementum was possible. Acellular cementum demonstrated characteristic "brush border" appearance under polarizing microscope because acellular cementum rarely shows intrinsic collagen bundles, and the extrinsic fibres, which are arising from the PDL and getting incorporated into the cementum, exhibit a visual loss since these fibres cannot be seen by rotation of the polaroids. A possible explanation for this phenomenon is that the fibres change their direction. If the new direction of these fibres were perpendicular to the surface of the slide, they would not be birefringent since collagen is isotropic when viewed from this aspect. Cellular cementum mainly exhibited thin parallel fibre arrangement and/ or quilt-like, which consisted of short lengths of fine collagen bundles grouped in random fashion. ${ }^{8}$ Cundiff 6 stated that mineralization is an inherent potential of periodontal ligament and/or periosteum, which would further lead us to dwell on the reasons of their pathogenesis. Two schools of thought have been professed to explain the histogenesis. ${ }^{16}$ The first group of researchers believed that POF develops from cells of PDL/periosteum, which has been accepted by most, whereas other group believed that these lesions were simply a more mature variant of pyogenic granuloma. Long-standing pyogenic granuloma showing maturation and calcifications in their histopathology could mimic an overall picture of POF, which may be due to the metaplastic change depicted in the fibroblasts.

Polarizing microscopy clearly delineated between bone and cementum; of the 15 cases studied, none of the cases showed the presence of dystrophic calcification. Such calcifications representing degenerative tissue are seen in other reactive gingival lesions such as pyogenic granuloma. When these dystrophic calcifications are seen under polarizing microscopy, these calcifications are nonpolarizable. Thus, these two factors further reiterate the origin of POF 
Table 3 Polarizing microscopy findings

\begin{tabular}{|c|c|c|}
\hline \multirow[t]{2}{*}{ Case no } & \multicolumn{2}{|l|}{ Polarizing pattern of mineralized tissues } \\
\hline & Bone & Cementum \\
\hline I & Random arrangement - woven bone & - \\
\hline 2 & Random arrangement - woven bone & - \\
\hline \multirow[t]{2}{*}{3} & Random arrangement - woven bone & - \\
\hline & Thick parallel lamellations - lamellar bone & \\
\hline 4 & Small foci showing random arrangement - woven bone & - \\
\hline \multirow[t]{2}{*}{5} & - & Predominantly brush border - acellular cementum \\
\hline & & Thin parallel - cellular cementum \\
\hline 6 & Thick parallel lamellations - lamellar bone & Quilt pattern - cellular cementum \\
\hline 7 & Thick parallel lamellations - lamellar bone & Quilt pattern and thin parallel arrangement - cellular cementum \\
\hline 8 & Random arrangement - woven bone & - \\
\hline 9 & Random arrangement - woven bone & - \\
\hline \multirow[t]{2}{*}{10} & Random arrangement - woven bone & - \\
\hline & Thick parallel lamellations - lamellar bone & \\
\hline $\mathrm{II}$ & Random arrangement - woven bone & - \\
\hline \multirow[t]{2}{*}{12} & - & Predominantly brush border - acellular cementum \\
\hline & & Thin parallel - cellular cementum \\
\hline 13 & Thick parallel lamellations - lamellar bone & Quilt pattern and thin parallel arrangement - cellular cementum \\
\hline 14 & Random arrangement - woven bone & - \\
\hline 15 & Random arrangement - woven bone & - \\
\hline
\end{tabular}

from the undifferentiated cells of periodontal ligament. The undifferentiated mesenchymal cells have an inherent proliferative potential; this can account for the high recurrence rate (13\% according to Lee, ${ }^{4} 14.2 \%$ according to Kenney, ${ }^{5}$ and $16 \%$ according to $\mathrm{Cundiff}^{6}$ ) seen in POF. The presence of these lesions in the interdental area may contribute to the incomplete removal due to the paucity of access. Thus, a deep excision whenever possible to the base of periosteum and affected PDL should be advocated to minimize the unexpectedly high recurrence rate for these benign fibroblastic lesions.

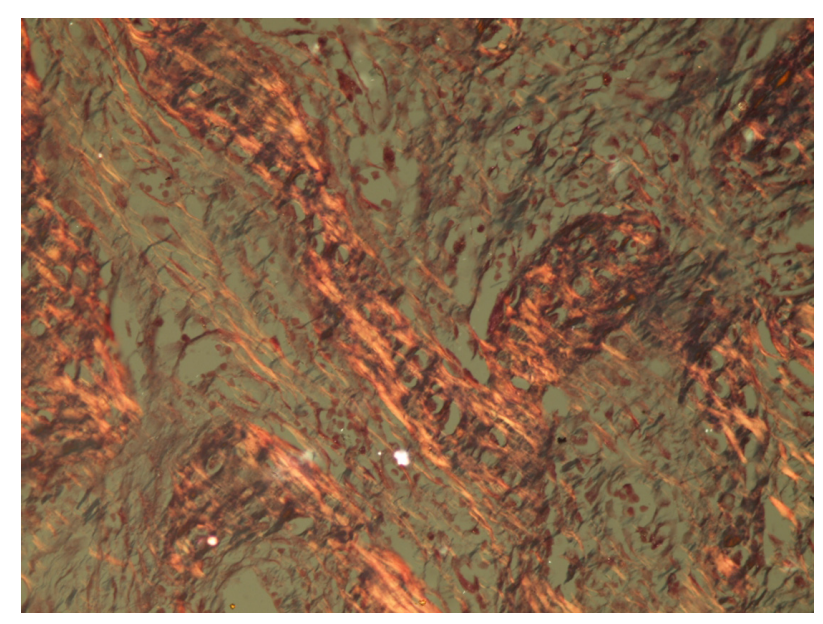

Figure 4 Section showing woven bone (random arrangement) under polarized light (van Gieson, original magnification $\times 40$ ).

\section{Conclusion}

Studies carried out with the help of polarizing microscope to decipher the presence of the kind of mineralized tissue has led to the finding of the definitive presence of cementum, bone, and a combination of the two. The presence of the tissue architecture and the type of cell also further emphasizes that these growths are probably not metaplastic in origin but arise de novo. This would lead to an analysis that could suggest the origin of these lesions to be in deeper structures, which are in close association with the tooth. Further studies are required to relate the clear association between the undifferentiated

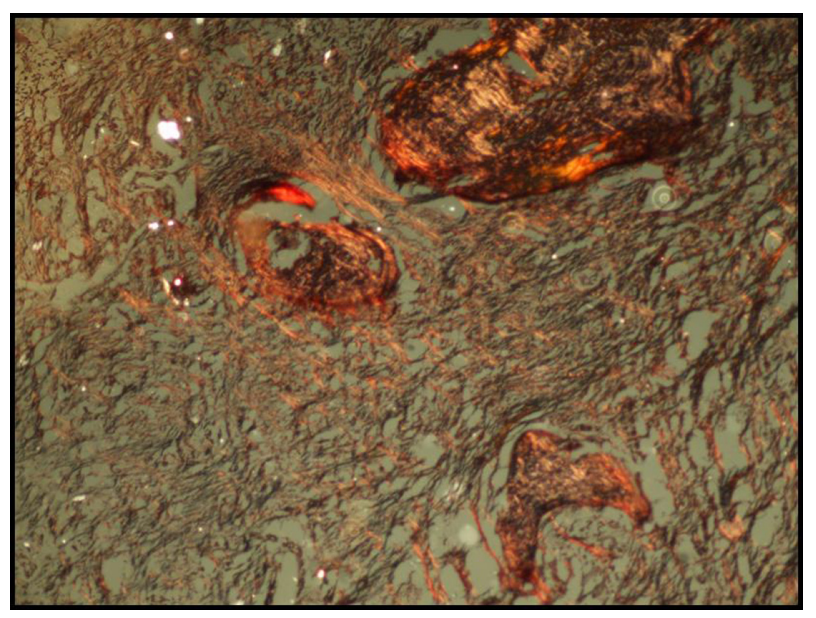

Figure $\mathbf{5}$ Section showing lamellar bone and cementum under polarized light (van Gieson, original magnification $\times 40$ ). 


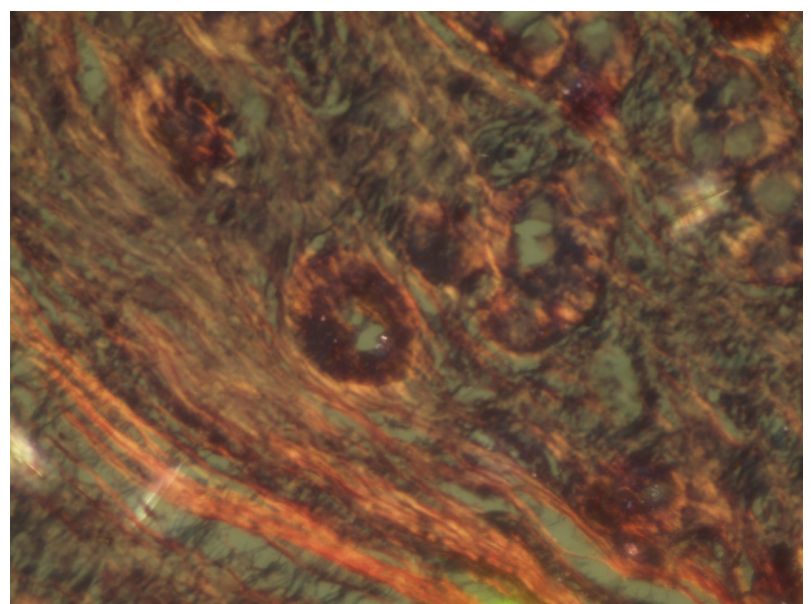

Figure 6 Section showing cemental masses (acellular cementum with typical brush border appearance) under polarized light (van Gieson, original magnification $\times 40$ ).

cells of PDL giving rise to POF to emphatically hypothesize the present findings.

\section{Disclosure}

The authors report no conflicts of interest in this work.

\section{References}

1. Buchner A, Hansen LS. The histomorphologic spectrum of peripheral ossifying fibroma. Oral Surg Oral Med Oral Pathol. 1987;63(4):452-461.

2. Poon CK, Kumar PC, Chao SY. Giant peripheral ossifying fibroma of the maxilla: report of a case. J Oral Maxillofac Surg. 1995;53:695-698.
3. Hamner EJ, Scofield HH, Cornyn J. Benign fibro-osseous jaw lesions of periodontal membrane origin. An analysis of 249 cases. Cancer. 1968;22(4):861-878.

4. Lee KW. The fibrous epulis and related lesions. Granuloma pyogenicum, "Pregnancy tumor", fibro-epithelial polyp and calcifying fibroblastic granuloma. A clinico-pathological study. Periodontics. 1968;6:277-292.

5. Kenney JN, Kaugars GE, Abbey LM. Comparison between the peripheral ossifying fibroma and peripheral odontogenic fibroma. J Oral Maxillofac Surg. 1989;47:378.

6. Cundiff EJ. Peripheral Ossifying Fibroma: A Review of 365 Cases [thesis]. Indiana University, USA; 1972.

7. Bancroft JD, Gamble M. Theory and Practice of Histological Techniques. 5th ed. London, UK: Churchill Livingstone; 2002.

8. Giansanti JS. The pattern and width of the collagen bundles in bone and cementum. Oral Surg. 1970;30(4):508-514.

9. Gardner DG. The peripheral odontogenic fibroma: an attempt at classification. Oral Surg Oral Med Oral Pathol. 1982;54:40.

10. Sousa SCOM, Mesquita RA, Araujo NS. Proliferative activity in peripheral ossifying fibroma and ossifying fibroma. J Oral Pathol Med. 1998;27:64-67.

11. Bhasker SN, Jacoway JR. Peripheral fibroma and peripheral fibroma with calcification: report of 376 cases. J Am Dent Assoc. 1966;73:1312-1320.

12. Waldron CA. Fibro-osseous lesions of the jaws. J Oral Maxillofac Surg. 1993;51:828-835.

13. Eversole LR, Rovin S. Reactive lesions of the gingiva. J Oral Pathol. 1972;1:30-38.

14. Kumar KSS, Saravanan R, Jorgensen GM, Shuler FC, Sedghizadeh PP. Multicentric peripheral ossifying fibroma. J Oral Sci. 2006; 48(4): 239-243.

15. Waldron AC, Giansanti SJ. Benign fibro-osseous lesions of the jaws: a clinical-radiologic-histologic review of sixty-five cases. Oral Surg. 1973;35(3):340-350.

16. Neville BW, Damm DD, Allen CM, Bouquot JE. Oral and Maxillofacial Pathology. 3rd ed. Noida, India: Elseiver; 2009.
Pathology and Laboratory Medicine International

\section{Publish your work in this journal}

Pathology and Laboratory Medicine International is a peer-reviewed, open access journal focusing on innovative basic research and translational research related to pathology or human disease. The journal includes original research, updates, case reports, reviews and commentaries on current controversies. The Academic Sponsor

\section{Dovepress}

of this journal is the Chinese American Pathology Association (CAPA). The manuscript management system is completely online and includes a very quick and fair peer-review system. Visit http://www.dovepress.com/testimonials.php to read real quotes from published authors. 